\title{
Green synthesis of new chiral 1-(arylamino)imidazo- [2,1-a]isoindole-2,5-diones from the corresponding $\alpha$-amino acid arylhydrazides in aqueous medium
}

\author{
Nadia Bouzayani ${ }^{1}$, Jamil Kraïem ${ }^{*}$, Sylvain Marque ${ }^{*}$, Yakdhane Kacem ${ }^{* 1}$, \\ Abel Carlin-Sinclair ${ }^{4}$, Jérôme Marrot $^{3}$ and Béchir Ben Hassine ${ }^{1}$
}

\section{Full Research Paper}

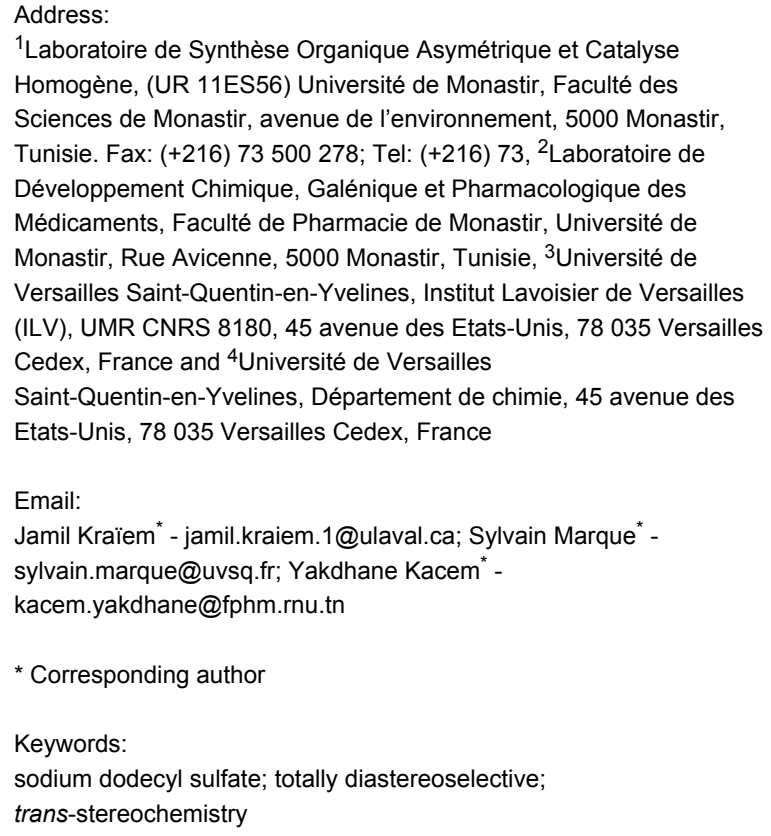

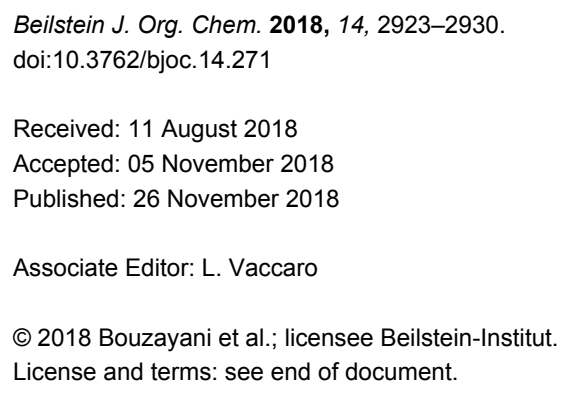

\begin{abstract}
New chiral 1-(arylamino)imidazo[2,1-a]isoindole-2,5-dione derivatives were obtained in good to excellent yields via the cyclocondensation of 2-formylbenzoic acid and various $\alpha$-amino acid arylhydrazides using water as the solvent in the presence of sodium dodecyl sulfate as the surfactant and under simple and minimum manipulation, without purification. The reaction is totally diastereoselective and gives access to the nitrogenated tricyclic core with a relative trans stereochemistry.
\end{abstract}

\section{Introduction}

Tricyclic compounds, such as imidazo[2,1-a]isoindol-5-ones, are widely distributed in nature and possess several biological activities. In 1967, Geigy described the preparation of 1,2,3,9b- tetrahydro-5 $H$-imidazo[2,1-a]isoindol-5-ones I which are recognized as anti-inflammatory and analgesic agents [1]. Other compounds, such as $1 H$-imidazo[2,1-a]isoindole-2,5-diones II 
have been known as an important herbicides for bud growth inhibition [2-6] and plant growth regulation [7-11]. Several research groups have turned to the synthesis of these structural analogues (Figure 1) [12]. For example, the stereoselective synthesis of chiral $1 H$-imidazo[2,1- $a$ ]isoindole-2,5 $(3 H, 9 \mathrm{~b} H)$-diones [6] and 1,2,3,9b-tetrahydro-5 $H$-imidazo[2,1-a]isoindol-5-ones [13] has been described by Katritzky et al. using $\alpha$-aminoamides and diamines, respectively.

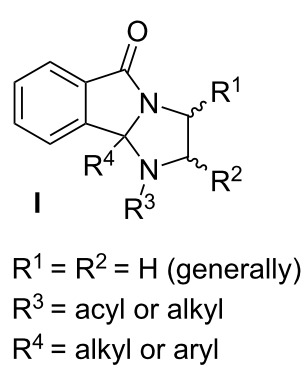

ongoing efforts directed toward the development of environmentally safe conditions for the synthesis of heterocyclic compounds starting from natural (L)- $\alpha$-amino acids [19-23] and the reactivity of $\alpha$-amino acid phenylhydrazides [24,25], we now report a green and eco-friendly procedure for the synthesis of new chiral 1-(arylamino)-1H-imidazo[2,1-a]isoindole2,5(3H,9bH)-diones (Scheme 1).<smiles>[R2]OC(=O)C([R2])N</smiles>

Scheme 1: Strategy for the formation of 1-(arylamino)-1H-imidazo[2,1a]isoindole-2,5(3H,9bH)-diones.

\section{Results and Discussion Synthesis}

The starting (L)- $\alpha$-amino acid arylhydrazides 3 were prepared in a manner similar to the well-known procedures [26-28], improving the amount of the added arylhydrazine $\mathbf{2}$ down to 2.5 equiv (Scheme 2, Table 1 ) in a sealed tube in the presence of $\mathrm{Et}_{3} \mathrm{~N}$ and under solvent-free conditions. From green chemistry point of view, this enhanced procedure appears to be a good alternative of the precedents for the synthesis of hydrazides 3a-m [26-29]. Moreover, the phenylglycine phenylhydrazide (3d), (L)-cysteine phenylhydrazide (3g), (L)-tyrosine phenylhydrazide (3j), (L)-alanine 4-chlorophenylhydrazide (3k), (L)-phenylglycine 4-chlorophenylhydrazide (3l) and (L)-phenylalanine 4-chlorophenylhydrazide (3m) were synthesized for the first time in this work.

Verardo et al. [29] have shown that refluxing $\alpha$-amino acid phenylhydrazides with levulinic acid in toluene led to the corresponding dihydro- $1 H$-pyrrolo[1,2- $a]$ imidazole-2,5-diones. These authors explained clearly the behavior of the solvent and its influence in the reaction. In addition, substituted 1-hydroxy$1 H$-imidazo[2,1-a] isoindole-2,5(3H,9bH)-diones have been along with the decreases of waste and cost. As a part of our proaches through the simplification of chemical processing

Also, the imidazo[2,1-a]isoindole-2,5-dione derivatives of primaquin have been synthesized from $\alpha$-amino acids [14]. Focusing on the $1 H$-imidazo[2,1-a]isoindolone skeleton, 1,2-diketones, 2-formylbenzoic acid and ammonium acetate [15]. These methodologies usually use toxic solvents such as [16], dichloromethane and some catalyst such as $p c$ manage undesirable Recently, such synthetic methods utilizing hazardous solvents and reagents and generating toxic waste have become discouraged and there have been many efforts to develop safer and environmentally benign alternatives. The green chemistry concept emerged in 1990 [18] with the aim at developing cleaner ap-

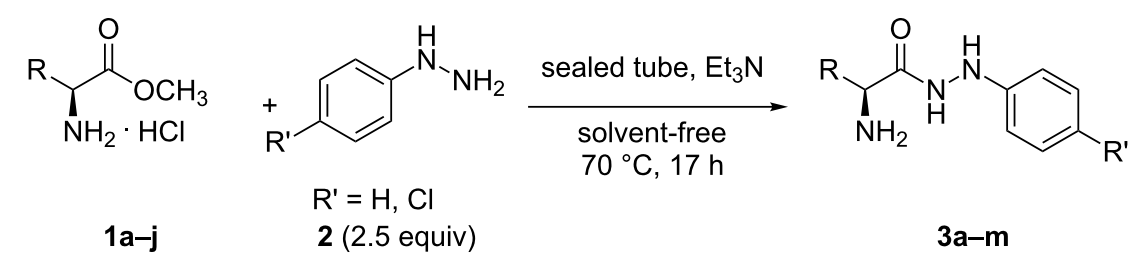




\begin{tabular}{|c|c|c|c|c|c|}
\hline entry & product (mol \%) & $\mathrm{R}$ & $\mathrm{R}^{\prime}$ & yield $[\%]$ & $\mathrm{mp}\left[{ }^{\circ} \mathrm{C}\right]$ \\
\hline 1 & $3 a$ & $\mathrm{Me}$ & $\mathrm{H}$ & 87 & $122-124$ \\
\hline 2 & $3 b$ & $\mathrm{iPr}$ & $\mathrm{H}$ & 80 & $138-140$ \\
\hline 3 & $3 c$ & $\mathrm{iBu}$ & $\mathrm{H}$ & 70 & $152-154$ \\
\hline 4 & $3 d^{b}$ & $\mathrm{Ph}$ & $\mathrm{H}$ & 83 & $138-140$ \\
\hline 5 & $3 e$ & $\mathrm{Bn}$ & $\mathrm{H}$ & 93 & $142-144$ \\
\hline 6 & $3 f$ & $\left(\mathrm{CH}_{2}\right)_{2} \mathrm{SMe}$ & $\mathrm{H}$ & 81 & $128-130$ \\
\hline 7 & $3 g$ & $\mathrm{CH}_{2} \mathrm{SH}$ & $\mathrm{H}$ & 71 & $98-100$ \\
\hline 8 & $3 \mathrm{~h}$ & $\mathrm{CH}_{2} \mathrm{OH}$ & $\mathrm{H}$ & 71 & $163-165$ \\
\hline 9 & $3 \mathbf{i}$ & $3-\mathrm{CH}_{2}-1 \mathrm{H}$-indole & $\mathrm{H}$ & 80 & $168-170$ \\
\hline 10 & $3 \mathbf{j}$ & $\mathrm{CH}_{2} \mathrm{C}_{6} \mathrm{H}_{4} \mathrm{OH}$ & $\mathrm{H}$ & 77 & $134-136$ \\
\hline 11 & $3 k$ & $\mathrm{Me}$ & $\mathrm{Cl}$ & 69 & $128-130$ \\
\hline 12 & 31 & $\mathrm{Ph}$ & $\mathrm{Cl}$ & 70 & $135-137$ \\
\hline 13 & $3 m$ & $\mathrm{Bn}$ & $\mathrm{Cl}$ & 74 & $140-142$ \\
\hline
\end{tabular}

aYield of the isolated product. ${ }^{\mathrm{b}}$ The compound $\mathbf{3} \mathbf{d}$ was obtained as a racemic mixture.

synthesized by the condensation of (L)- $\alpha$-aminohydroxamic acids and 2-formylbenzoic acid under the same conditions [30]. Thus, they choose toluene as the best solvent for this reaction. To prepare the new chiral 1-(arylamino)imidazo[2,1- $a$ ]isoindole-2,5-diones 5a-m under greener conditions, we investigated the reaction in nontoxic solvents such as water and dimethyl carbonate (DMC). Indeed, DMC is well-known as safe reagent and solvent that has been used for many green applications [31-33]. On the other hand, water is a simply and environmen- tally benign solvent and interest has increasingly turned to it as the greenest solvent of chemical reactions [34]. In order to find the best reaction conditions, a model reaction was chosen using (L)-alanine phenylhydrazide (3a, Scheme 3), and the results of these optimized studies were summarized in Table 2.

The best result was obtained when a mixture of hydrazide $\mathbf{3 a}$ and formylbenzoic acid 4 was heated at $120{ }^{\circ} \mathrm{C}$ (oil bath) using water as the solvent in the presence of SDS $(10 \%)$ as the surfac-<smiles>CC(N)C(=O)NNc1ccccc1</smiles>

Scheme 3: Cyclocondensation of 2-formylbenzoic acid (4) with (L)-alanine phenylhydrazide (3a).

Table 2: Optimization of the reaction conditions for the cyclocondensation of 2 -formylbenzoic acid (4) with (L)-alanine phenylhydrazide (3a). ${ }^{a}$

\begin{tabular}{|c|c|c|c|c|}
\hline entry & additive [mol \%] & time $[\mathrm{h}]$ & conditions $^{a}$ & yields [\%] \\
\hline 1 & - & 4 & $\mathrm{DMC}^{\mathrm{b}}$ & 82 \\
\hline 2 & - & 10 & $\mathrm{H}_{2} \mathrm{O}$ & 72 \\
\hline 3 & SDS [5] & 10 & $\mathrm{H}_{2} \mathrm{O}$ & 77 \\
\hline 4 & SDS [10] & 10 & $\mathrm{H}_{2} \mathrm{O}^{\mathrm{C}}$ & 90 \\
\hline 5 & - & 10 & neat $^{d}$ & 89 \\
\hline 6 & - & 4 & toluene $\mathrm{e}^{\mathrm{e}}$ & 88 \\
\hline
\end{tabular}

${ }^{a}$ General conditions for all the six entries: (L)-alanine phenylhydrazide $(0.66 \mathrm{mmol}), 2$-formylbenzoic acid $(0.66 \mathrm{mmol}), 120{ }^{\circ} \mathrm{C} .{ }^{\mathrm{b}} \mathrm{Conditions}$ : DMC $(1.5 \mathrm{~mL})$ in sealed tube. ${ }^{\mathrm{C} C o n d i t i o n s: ~ w a t e r ~}(1.5 \mathrm{~mL})$ and sodium dodecyl sulfate (SDS) in sealed tube. ${ }^{\mathrm{d}}$ Conditions: in sealed tube. ${ }^{\mathrm{e}}$ Conditions: toluene $(3 \mathrm{~mL})$, under argon. 
tant for $10 \mathrm{~h}$ leading to a $90 \%$ yield in $\mathbf{5 a}$. To demonstrate the generality of this method, we next investigated the scope of this reaction under the optimized conditions. A variety of the 1-(arylamino)imidazo[2,1-a]isoindole-2,5-diones $\mathbf{5 b}$-m were prepared and the obtained results are summarized in Scheme 4. The mild conditions of the reaction gave access to the tricyclic compounds 5a-m providing similar yields, regardless the amino acid residue is. A weak acidic function was well-tolerated yielding $5 \mathbf{j}$ with $66 \%$. Bulky groups did not roughly affect the efficiency of the reactivity $(\mathbf{5 b}, \mathbf{5 c})$.

The new approach described in this work for the preparation of compounds 5a-m has the following advantages: (i) notably, under the reaction conditions described above, we have never<smiles>[R]c1ccc(NN2C(=O)C([R])N(Nc3ccc([R])cc3)C2C(=O)c2ccccc2C)cc1</smiles><smiles>CC1C(=O)N(N)[C@H]2c3ccccc3C(=O)N12</smiles>

5a 90\%; dr 1:0; er 99.3:0.7<smiles>CN1C(=O)N2C(=O)c3ccccc3[C@]1(C)[C@@H]2Cc1ccccc1</smiles>

5e $78 \%$; dr 1:0; er 99:1<smiles>O=C1c2ccccc2[C@]2([C@H]3COCCO3)C(=O)[C@H](Cc3c[nH]c4ccccc34)N12</smiles>

5i $73 \%$; dr 1:0; er 94:6<smiles>CC(C)[C@H]1C(=O)N(N)[C@]2(c3ccccc3)c3ccccc3C(=O)N12</smiles>

5b 70\%; dr 1:0; er 1:0

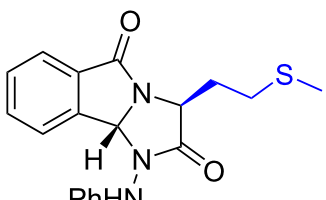

5f 71\%; dr 1:0; er 99:1<smiles>O=C1[C@H](Cc2ccc(O)cc2)N2C(=O)c3ccccc3[C@H]2N1Nc1ccccc1</smiles><smiles>CC1C(=O)N(Nc2ccc(Cl)cc2)[C@H]2c3ccccc3C(=O)N12</smiles>

5k 69\% dr 1:0; er 1:0<smiles>NN1C(=O)[C@@H](c2ccccc2)N2C(=O)c3ccccc3[C@@H]12</smiles>

5d 81\%; dr 1:0; er 1:1<smiles>NN1C(=O)C(CO)N2C(=O)c3ccccc3[C@H]12</smiles>

5h 77\%; dr 1:0; er 1:0<smiles>O=C1[C@H](c2ccccc2)N2C(=O)c3ccccc3[C@H]2N1Nc1ccc(Cl)cc1</smiles>

5l 70\% dr 1:0; er 1:1<smiles>O=C1[C@H](Cc2ccccc2)N2C(=O)c3ccccc3[C@H]2N1Nc1ccc(Cl)cc1</smiles>

$5 \mathrm{~m} 74 \%$ dr $1: 0 ;$ er $1: 0$ 
observed the formation of degradation products. (ii) The reaction was performed in water, in the presence of SDS (sodium dodecyl sulfate) as the surfactant. Based on previous studies [35], the most effective method for ensuring the solubility of reactants in water is the use of surfactants that can form micelles with a hydrophobic core and a hydrophilic corona. (iii) This clean method afforded compounds $\mathbf{5 a}-\mathbf{m}$ without the need of additional purification such as column chromatography or recrystallization. (iv) The use of a sealed tube [36-43] obeys to four out of the twelve green chemistry principles: a cleaner and eco-friendly reaction profile with minimum of waste, solvent without negative environmental impact, shorter reaction time and safely work with a pressure tube canning prevent fires and emissions of hazardous compounds and toxic gas. (v) The reaction described in this work occurred with high atom efficiency (atom economy of 90\%) and produced only stoichiometric $\mathrm{H}_{2} \mathrm{O}$ as waste (E-factor of 0.1).

\section{Stereochemistry and mechanism}

The stereochemistries of $\mathbf{5 a}-\mathbf{m}$ were ascribed by NOE NMR experiments. By example using 5a depicted in Figure 2, the ${ }^{1} \mathrm{H}$ NMR spectrum showed that $\mathrm{H}(1)$ appears at $5.95 \mathrm{ppm}$ as a singlet and $\mathrm{H}(4)$ at $4.72 \mathrm{ppm}$ as a quadruplet. No distinct NOE effect was observed between $\mathrm{H}(1)$ and $\mathrm{H}(4)$, when either $\mathrm{H}(1)$ or H(4) was irradiated. A significant positive NOE effect was observed between $\mathrm{H}(1)$ and $\mathrm{H}(20)$. Thus, NOE analysis assumed that $\mathrm{H}(1)$ is in a trans-orientation with $\mathrm{H}(4)$.

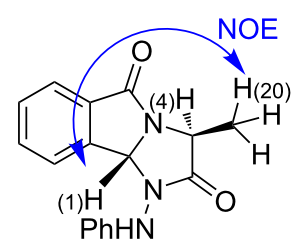

Figure 2: NOEs correlation showing the stereochemistry of the compound 5 a.

In addition, various crystallization tests were carried out in order to confirm the absolute stereochemistry by X-ray diffraction. The chiral 3-(2-(methylthio)ethyl)-1-(phenylamino)- $1 H$ imidazo[2,1-a] isoindole-2,5(3H,9bH)dione (5f) crystallized [44-49] using a mixture of $\mathrm{CH}_{2} \mathrm{Cl}_{2}$ /diethyl ether (3:1) as a single diastereoisomer with the $(3 S, 9 R)$ configuration (Figure 3$)$ showing clearly the trans relative stereochemistry.

The dihedral angle value of $-163.1^{\circ}$ for $\mathrm{H}(1)-\mathrm{C}(1)-\mathrm{C}(4)-\mathrm{H}(4)$ close to the anti-planarity corroborates the expected non correlation between $\mathrm{H}(1)$ and $\mathrm{H}(4)$ in the NOE experiment. The structure contains two carbonyl moieties $\mathrm{C}(6)-\mathrm{O}(2)$ and

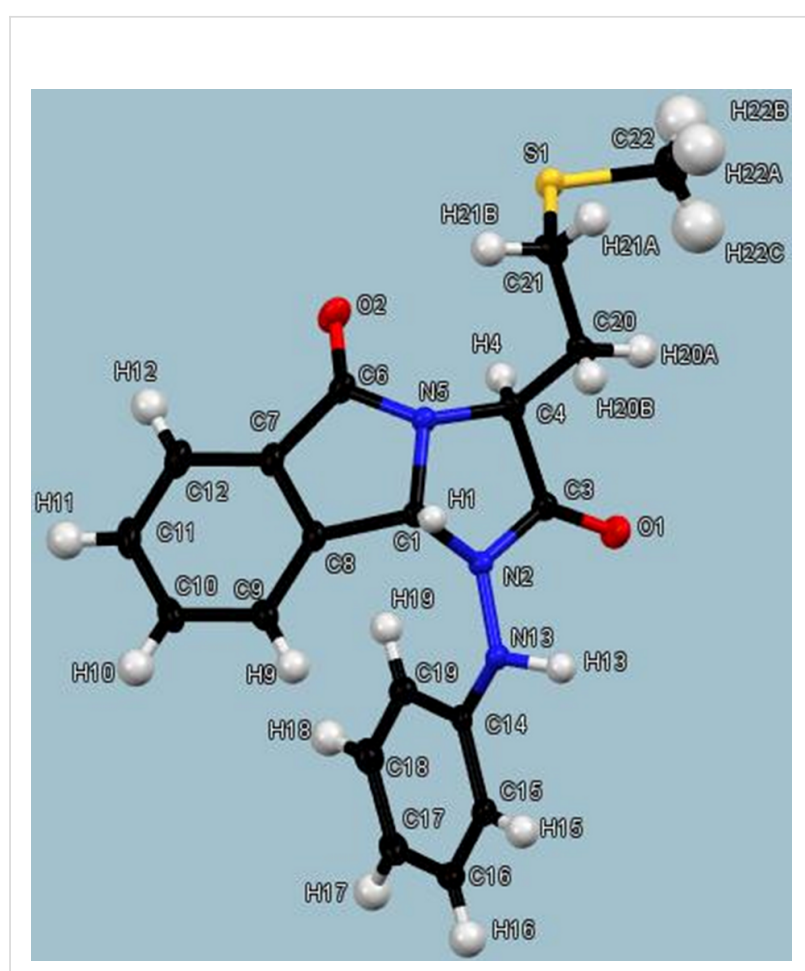

Figure 3: X-ray crystal structure of $\mathbf{5 f}$ shown at the $30 \%$ probability level.

$\mathrm{C}(3)-\mathrm{O}(1)$ with similar distances of 1.222 and $1.218 \AA$, respectively. The intramolecular hydrogen bond $\mathrm{O}(1)-\mathrm{H}(13)$ remains strong in the nitrogenated tricycle $(2.579 \AA)$ vis-à-vis of the starting hydrazide.

Analyzing the mechanism of the reaction between the 2-formylbenzoic acid $\mathbf{4}$ and $\alpha$-amino acid arylhydrazides 3 , we assumed that the first steps lead to the formation of the imine intermediate $\mathbf{A}$, which is the result of the nucleophile addition of the $\alpha$-amino group on the most electrophilic center in 4 . This iminocarboxylic acid form likely evolves to its iminium-carboxylate form $\mathbf{B}$ [50]. This last intermediate involves the existence of two possible transition states for the cyclization of the imidazolidinone core of which one of them is favored by an intramolecular hydrogen bond (Scheme 5). This control is the main difference with the known reaction [51] between the hydrazides 3 and the phthalaldehydes in which two diasteroisomers have been observed. If the amino acid residue ( $\mathrm{R}$ on the Scheme 5) enough implicates steric hindrance with the carboxyaromatic part of $\mathbf{B}$, the pathway with disfavored transition state becomes unlikely and then the selectivity is important. Our model is in agreement with the diasteroisomeric ratio results. In fact, a total diastereoselectivity was observed, including $\mathbf{5 d}(\mathrm{R}=\mathrm{Ph})$ since an epimerization of the initial asymmetric center was observed, therefore racemic trans-isomers were obtained in this case. Interest- 
<smiles>[R]C(N=Cc1ccccc1C(=O)O)C(=O)NNN=Cc1ccccc1C(=O)O</smiles>

3a-m

A

B

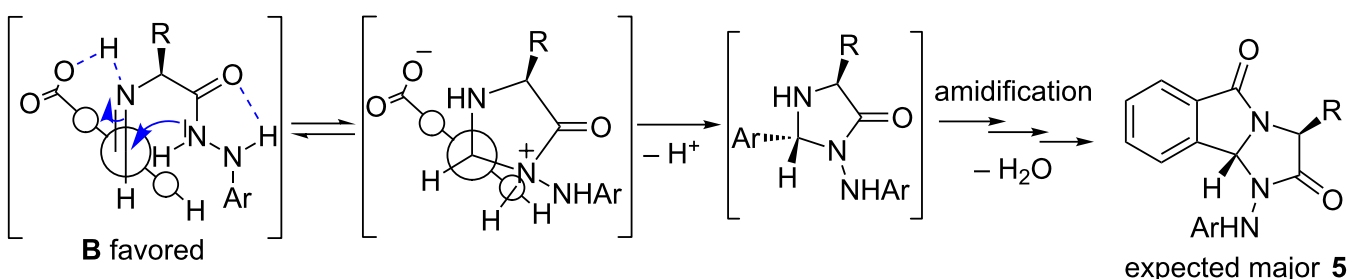

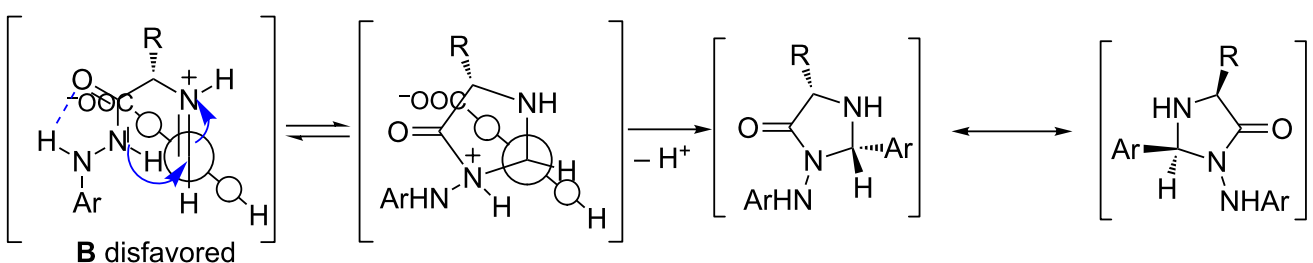

In Newman projection:

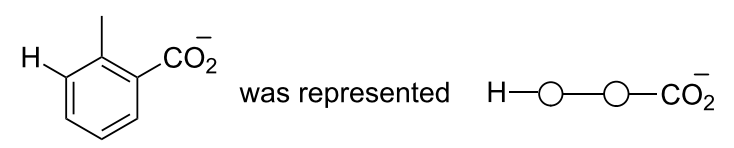

Ar: $\mathrm{Ph}, 4-\mathrm{Cl}-\mathrm{Ph}$

Scheme 5: Proposed partial mechanism with a selectivity model.

ingly, acidic (phenolic 5j) and basic moieties (as indolyl 5i) on the amino acid residue did not affect the selectivity.

\section{Conclusion}

In summary, we have developed environmentally safe conditions for the synthesis of new chiral 1-(arylamino)- $1 H$ imidazo[2,1- $a$ ] isoindole-2,5(3H,9bH)-diones in good yields using water as the solvent in sealed tube. The aspects of greenness and good results make this methodology a practical and atom economical alternative in the whole of the processing since the syntheses of the $\alpha$-amino acid arylhydrazide precursors behave this greener aspect. Once more, the processing includes this eco-friendly way up to have the compounds in hand since simple precipitation allows to isolate the nitrogenated tricyclic compounds; no purification is needed. The model for the key step of the cyclization clearly explains the stereochemistries, which are observed with a total trans-diastereoselectivity controlled by intramolecular hydrogen bonds.

\section{Supporting Information}

\section{Supporting Information File 1}

Experimental procedures, spectroscopic and analytical data and copies of spectra of the products.

[https://www.beilstein-journals.org/bjoc/content/ supplementary/1860-5397-14-271-S1.pdf]

\section{Supporting Information File 2}

Crystallographic information for compound $\mathbf{5 f}$.

[https://www.beilstein-journals.org/bjoc/content/ supplementary/1860-5397-14-271-S2.pdf]

\section{Supporting Information File 3}

HPLC analysis of the products.

[https://www.beilstein-journals.org/bjoc/content/ supplementary/1860-5397-14-271-S3.pdf] 


\section{Acknowledgements}

The authors thank the DGRST (Direction Générale de la Recherche Scientifique et Technologique) of the Tunisian Ministry of Higher Education and Scientific research and Technology for financial support of this research.

\section{ORCID ${ }^{\circledR}$ iDs}

Yakdhane Kacem - https://orcid.org/0000-0002-6725-8861

Abel Carlin-Sinclair - https://orcid.org/0000-0002-4391-4342

\section{References}

1. Geigy, J. R. Neth. Appl. 6,613,264, 1967. Chem. Abstr. 1967, 67, 82204q.

2. Graf, W. Swiss Patent 481,123, 1969. Chem. Abstr. 1970, 72, 100709 t.

3. Los, M. U.S. Patent USP 4,041,045, 1977. Chem. Abstr. 1977, 87, 168034j.

4. Ashkar, S. A. U.S. Patent USP 4,090,860, 1978. Chem. Abstr. 1978, 89, 192503y.

5. Ashkar, S. A. U.S. Patent USP 4,067,718, 1978 Chem. Abstr. 1978, 88, 165485s.

6. Ashkar, S. A. U.S. Patent USP 4,093,441, 1978. Chem. Abstr. 1979, 90, 49647p.

7. Katritzky, A. R.; Mehta, S.; He, H.-Y.; Cui, X. J. Org. Chem. 2000, 65, 4364-4369. doi:10.1021/jo000219w

8. Polniaszek, R. P.; Belmont, S. E. J. Org. Chem. 1991, 56, 4868-4874. doi:10.1021/jo00016a013

9. Meyers, A. I.; Seefeld, M. A.; Lefker, B. A.; Blake, J. F.; Williard, P. G. J. Am. Chem. Soc. 1998, 120, 7429-7438. doi:10.1021/ja980614s

10. Burgess, L. E.; Meyers, A. I. J. Am. Chem. Soc. 1991, 113, 9858-9859. doi:10.1021/ja00026a026

11. Burgess, L. E.; Meyers, A. I. J. Org. Chem. 1992, 57, 1656-1662. doi:10.1021/jo00032a012

12. Katritzky, A. R.; Xu, Y.-J.; He, H.-Y.; Steel, P. J. J. Chem. Soc., Perkin Trans. 1 2001, 1767-1770. doi:10.1039/b104060j

13. Katritzky, A. R.; He, H.-Y.; Verma, A. K. Tetrahedron: Asymmetry 2002, 13, 933-938. doi:10.1016/s0957-4166(02)00220-3

14. Gomes, P.; Araújo, J. M.; Rodrigues, M.; Vale, N.; Azevedo, Z.; lley, J.; Chambel, P.; Morais, J.; Moreira, R. Tetrahedron 2004, 60, 5551-5562. doi:10.1016/j.tet.2004.04.077

15. Hosseini-Zare, M. S.; Mahdavi, M.; Saeedi, M.; Asadi, M.; Javanshir, S.; Shafiee, A.; Foroumadi, A. Tetrahedron Lett. 2012, 53, 3448-3451. doi:10.1016/j.tetlet.2012.04.088

16. Katritzky, A. R.; He, H.-Y.; Jiang, R. Tetrahedron Lett. 2002, 43, 2831-2833. doi:10.1016/s0040-4039(02)00350-7

17. Ramirez, A. Agrees to Purchase Part of American Cyanamid, Wall Street Journal, June 1990, 14.

18. Kacem, Y.; Kraiem, J.; Kerkeni, E.; Bouraoui, A.; Ben Hassine, B. Eur. J. Pharm. Sci. 2002, 16, 221-228. doi:10.1016/s0928-0987(02)00046-5

19. Aliyenne, A. O.; Khiari, J. E.; Kraïem, J.; Kacem, Y.; Ben Hassine, B. Tetrahedron Lett. 2006, 47, 6405-6408. doi:10.1016/j.tetlet.2006.06.148

20. Aliyenne, A. O.; Kraïem, J.; Kacem, Y.; Ben Hassine, B. Tetrahedron Lett. 2008, 49, 1473-1475. doi:10.1016/j.tetlet.2008.01.015
21. Tka, N.; Kraïem, J.; Kacem, Y.; Hajri, A.; Ben Hassine, B. C. R. Chim. 2009, 12, 1066-1071. doi:10.1016/j.crci.2008.09.004

22. Kacem, Y.; Ben Hassine, B. Tetrahedron Lett. 2012, 53, 5608-5610. doi:10.1016/j.tetlet.2012.08.008

23. Kacem, Y.; Ben Hassine, B. Tetrahedron: Asymmetry 2014, 25 , 252-257. doi:10.1016/j.tetasy.2013.12.002

24. Kacem, Y.; Ben Hassine, B. Heterocycles 2014, 89, 197-207. doi:10.3987/com-13-12878

25. Milne, H. B.; Most, C. F. J. Org. Chem. 1968, 33, 169-175. doi:10.1021/jo01265a032

26. Verardo, G.; Toniutti, N.; Gorassini, A.; Giumanini, A. G. Eur. J. Org. Chem. 1999, 2943-2948. doi:10.1002/(sici)1099-0690(199911)1999:11<2943::aid-ejoc2943>3.0. co;2-x

27. Verardo, G.; Geatti, P.; Martinuzzi, P.; Merli, M.; Toniutti, N. Eur. J. Org. Chem. 2003, 3840-3849. doi:10.1002/ejoc.200300251

28. Verardo, G.; Toniutti, N.; Giumanini, A. G. Can. J. Chem. 1998, 76, 1180-1187. doi:10.1139/v98-125

29. Verardo, G.; Geatti, P.; Merli, M.; Castellarin, E. E. Eur. J. Org. Chem. 2004, 2833-2839. doi:10.1002/ejoc.200400112

30. Hoshino, Y.; Oyaizu, M.; Koyanagi, Y.; Honda, K. Synth. Commun. 2013, 43, 2484-2492. doi:10.1080/00397911.2012.717162

31. Tundo, P.; Selva, M. Acc. Chem. Res. 2002, 35, 706-716. doi:10.1021/ar010076f

32. Rosamilia, A. E.; Aricò, F.; Tundo, P. J. Org. Chem. 2008, 73, 1559-1562. doi:10.1021/jo701818d

33. Kraïem, J.; Ghedira, D.; Ollevier, T. Green Chem. 2016, 18, 4859-4864. doi:10.1039/c6gc01394e

34. Kraïem, J.; Ollevier, T. Green Chem. 2017, 19, 1263-1267. doi:10.1039/c6gc03589b

35. Kobayashi, S.; Wakabayashi, T.; Nagayama, S.; Oyamada, H. Tetrahedron Lett. 1997, 38, 4559-4562. doi:10.1016/s0040-4039(97)00854-x

36. Kobayashi, S.; Wakabayashi, T. Tetrahedron Lett. 1998, 39, 5389-5392. doi:10.1016/s0040-4039(98)01081-8

37. Manabe, K.; Kobayashi, S. Synlett 1999, 547-548. doi:10.1055/s-1999-2685

38. Manabe, K.; Mori, Y.; Kobayashi, S. Tetrahedron 1999, 55, 11203-11208. doi:10.1016/s0040-4020(99)00642-0

39. Kobayashi, S.; Mori, Y.; Nagayama, S.; Manabe, K. Green Chem. 1999, 1, 175-177. doi:10.1039/a904439f

40. Kobayashi, S.; Manabe, K. Acc. Chem. Res. 2002, 35, 209-217. doi:10.1021/ar000145a

41. Landelle, H.; Laduree, D.; Cugnon de Servicourt, M.; Robba, M. Chem. Pharm. Bull. 1989, 37, 2679-2682. doi:10.1248/cpb.37.2679

42. Suzuki, T.; Kubomura, K.; Takayama, $\mathrm{H}$. J. Chem. Soc., Perkin Trans. 1 1997, 251-256. doi:10.1039/a604600b

43. Bhakuni, B. S.; Yadav, A.; Kumar, S.; Kumar, S. New J. Chem. 2014, 38, 827-836. doi:10.1039/c3nj01105d

44. SADABS, program for scaling and correction of area detector data; Sheldrick, G. M.: University of Göttingen, Germany, 1997.

45. Blessing, R. H. Acta Crystallogr., Sect. A: Found. Crystallogr. 1995, 51, 33-38. doi:10.1107/s0108767394005726

46. Sheldrick, G. M. Acta Crystallogr., Sect. A: Found. Crystallogr. 1990, 46, 467-473. doi:10.1107/s0108767390000277

47. SHELX-TL Software Package for the Crystal Structure Determination, 5.03; Sheldrick, G. M.: Siemens Analytical X-ray Instrument Division : Madison, WI USA, 1994. 
48. These data can be obtained free of charge via http://www.ccdc.cam.ac.uk/data_request/cif; $\mathrm{C}_{19} \mathrm{H}_{19} \mathrm{~N}_{3} \mathrm{O}_{2} \mathrm{~S}, M_{\mathrm{w}}=$ 353.43, orthorhombic, space group $P 2{ }_{1} 2{ }_{1} 2{ }_{1}$; dimensions: $a=6.3980(3)$ $\AA, b=14.3384(6) \AA, c=19.2989(9) \AA, V=1770.42(14) \AA^{3} ; Z=4 ; D x=$ $1.326 \mathrm{Mg} \mathrm{m}^{-3} ; \mu=0.200 \mathrm{~mm}^{-1} ; 33260$ reflections measured at $250 \mathrm{~K}$;

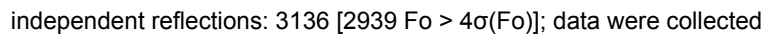
up to a $2 \Theta_{\max }$ value of $50.05^{\circ}(99.7 \%$ coverage). Number of variables: 231; $R_{1}=0.0322, w R_{2}=0.0807, S=1.078$; highest residual electron density 0.15 e. $\AA^{-3} ;$ CCDC $=1829108$.

49. Macrae, C. F.; Bruno, I. J.; Chisholm, J. A.; Edgington, P. R.; McCabe, P.; Pidcock, E.; Rodriguez-Monge, L.; Taylor, R. van de Streek, J.; Wood, P. A. J. Appl. Crystallogr. 2008, 41, 466-470. doi:10.1107/s0021889807067908

50. Bouzayani, N.; Marque, S.; Djelassi, B.; Kacem, Y.; Marrot, J.; Ben Hassine, B. New J. Chem. 2018, 42, 6389-6398. doi:10.1039/c7nj04597b

51. Bouzayani, N.; Talbi, W.; Marque, S.; Kacem, Y.; Ben Hassine, B. ARKIVOC 2018, No. iii, 229-239. doi:10.24820/ark.5550190.p010.297

\section{License and Terms}

This is an Open Access article under the terms of the Creative Commons Attribution License (http://creativecommons.org/licenses/by/4.0). Please note that the reuse, redistribution and reproduction in particular requires that the authors and source are credited.

The license is subject to the Beilstein Journal of Organic Chemistry terms and conditions:

(https://www.beilstein-journals.org/bjoc)

The definitive version of this article is the electronic one which can be found at: doi:10.3762/bjoc. 14.271 